\title{
Hypertrophic cardiomyopathy in three generations of a large Norwegian family A clinical, echocardiographic, and genetic study
}

\author{
HELGE HAUGLAND, OLE-JÖRGEN OHM, HELGE BOMAN, * ERIK THORSBY†
}

From the Medical Department, Section of Cardiology, and ${ }^{\star}$ Department of Medical Genetics, Haukeland Sykehus, University of Bergen; and the †Institute of Transplantation Immunology, University of Oslo, Norway

SUMMARY Hypertrophic cardiomyopathy is a heart muscle disease with an obscure aetiology. Data from four generations of a large family (71 members) are presented. The occurrence of hypertrophic cardiomyopathy among members of the two oldest generations was compatible with a pattern of autosomal dominant inheritance. Seven out of 14 siblings in the second generation had definite signs of or were clinically suspected of having hypertrophic cardiomyopathy. The severity and distribution of left ventricular hypertrophy varied, but three $(21 \%)$ brothers in generation II showed the classic picture of left ventricular outflow obstruction. Four siblings $(29 \%$ ) died suddenly aged $11,22,38$, and 40 years. A high incidence of the disease would have been expected in the two younger generations (41 members, aged 1-31 years), but only two, a 16 year old boy and a 17 year old girl had signs of asymmetric septal hypertrophy. Current diagnostic procedures, including $M$ mode and cross sectional echocardiography, are not sufficiently sensitive to identify young family members who may have preclinical hypertrophic cardiomyopathy.

No evidence for close genetic linkage between a postulated locus for hypertrophic cardiomyopathy and the major histocompatibility complex (antigens HLA-A, HLA-B, and HLA-DR) was found.

Hypertrophic cardiomyopathy is a disease of unknown cause. Several studies, however, have shown that the disease is common in some families, and that in such families hypertrophic cardiomyopathy may be transmitted as an autosomal dominant trait. ${ }^{1-4}$ An association between the trait and human leucocyte antigen HLA-DRW 4 has been reported in Japanese families, ${ }^{5}$ and Kishimoto et al have suggested that there may be two separate forms of the disease-a familial form linked to the HLA complex, and a non-linked sporadic type. ${ }^{6}$ In a study of 50 unrelated white North Americans with hypertrophic cardiomyopathy, however, Gardin et al did not find HLA-A, HLA-B, or HLA-C locus antigens useful as markers for this disease. ${ }^{7}$ Recent studies by Maron et al suggested the possibility of a

Requests for reprints to Dr Helge Haugland, Medical Department, Section of Cardiology, N-5016 Haukeland Sykehus, University of Bergen, Norway.

Accepted for publication 22 July 1985 pattern of autosomal dominant inheritance of hypertrophic cardiomyopathy in only 30 of 70 families. ${ }^{8}$ Maron et al also proposed that the wide range of phenotypic expressions observed may be due to genetic as well as to non-genetic causes. Genetic studies on hypertrophic cardiomyopathy have generally been carried out on rather small families, or on different families grouped together. In the present study we report the clinical, echocardiographic, and HLA findings in a large family through four generations. We studied the spectrum of phenotypic manifestations of a postulated single hypertrophic cardiomyopathy gene inherited as an autosomal dominant trait in this family. We also studied whether hypertrophic cardiomyopathy cosegregated with a particular HLA haplotype in this family. In that case, this HLA haplotype could be a presymptomatic predictor of the disease and might enable early medical intervention.

\section{Patients and methods}

The family studied consisted of four generations 
comprising a total of 71 members (Fig. 1). Physical and echocardiographic examinations were performed on all except two family members (III-6, III-8). In addition, a 12 lead electrocardiogram and chest $x$ ray films were taken on members of generations I, II, and III. M mode and cross sectional echocardiography were performed with an IREX III, phased array, ultrasonic scanner with a $2.4 \mathrm{MHz}$ handheld transducer. $M$ mode echocardiograms were recorded by means of a heat processed black and white strip chart recorder at a paper speed of $50 \mathrm{~mm} / \mathrm{s}$. The cross sectional echocardiographic examinations of the youngest individuals were performed with a Toshiba SAL 50 linear array ultrasonic scanner with a $5 \mathrm{MHz}$ transducer. The thickness of the ventricular wall was measured from the leading edges of the echoes with the transducer being held perpendicular to the chest wall in the standard position. ${ }^{9}$ The diagnostic criterion of hypertrophic cardiomyopathy or asymmetric septal hypertrophy in adults was increased thickness of the interventricular septum with a septum:posterior left ventricular wall ratio $>1.4$ in the absence of cardiac or systemic disease capable of producing left ventricular hypertrophy. A septum:posterior left ventricular wall ratio equal to 1.4 was regarded as nor$\mathrm{mal}$ in individuals aged $>20$ years, but as indicating hypertrophic cardiomyopathy in individuals aged $\leqslant 20$ years. In children the criterion of abnormal septal thickness was a measurement exceeding the age specific $95 \%$ confidence interval. ${ }^{10}$

The HLA antigens were determined by lymphocytotoxicity tests as previously described, ${ }^{11}$ with highly selected antisera defining 13 antigens of the HLA-A series, 22 of the HLA-B series, and 8 of the HLA-DR series. On the basis of the results of the

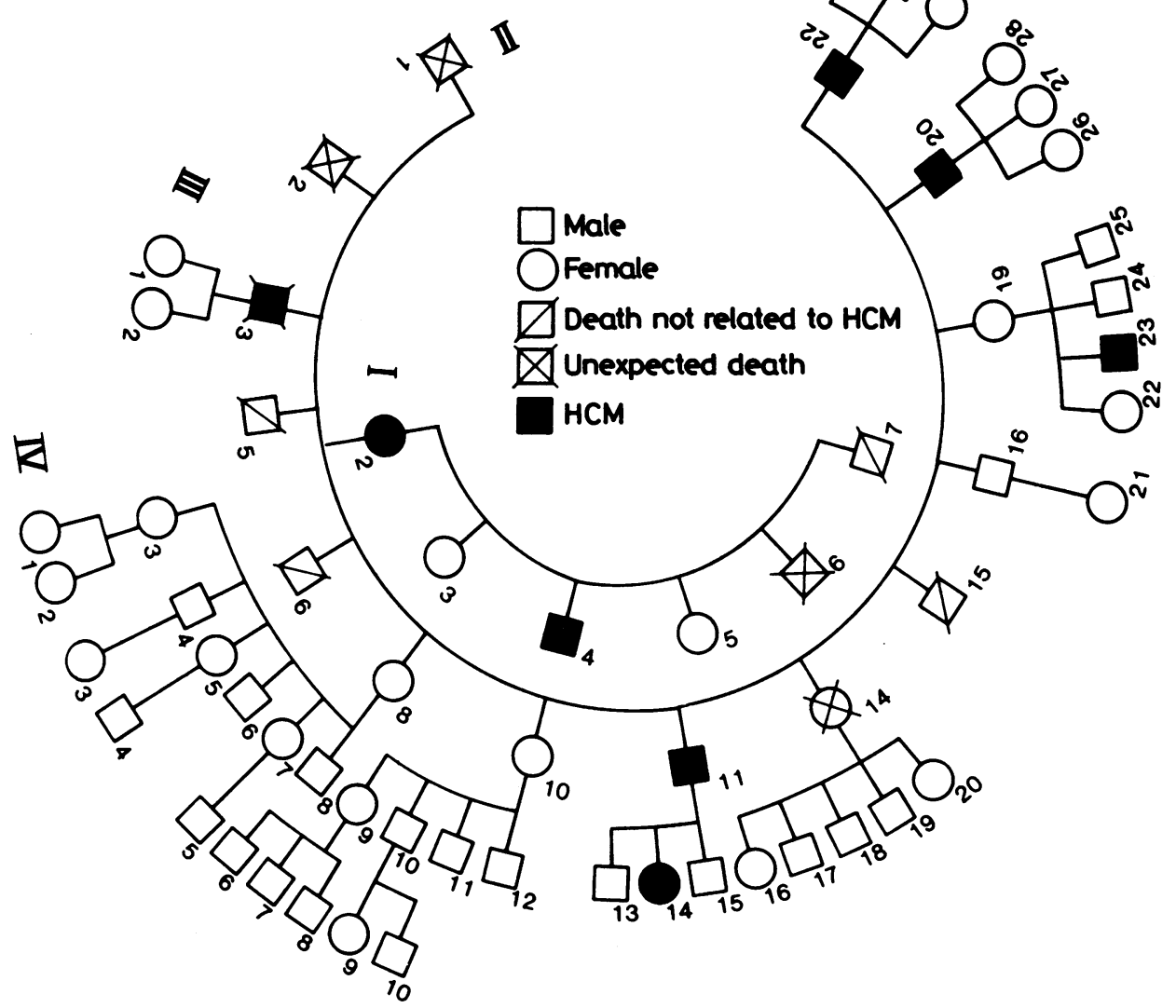

Fig. 1 Pedigree of the family. Roman numerals refer to generations. Each family member has an index number. HCM, hypertrophic cardiomyopathy. 
family typing, the HLA haplotypes could be deduced in some members of the family who were dead. An HLA haplotype is defined as the genetic information in HLA antigens carried by the HLAcomplex on each of the two chromosomes of pair number 6 .

\section{Results}

The results obtained in the four different generations are presented in chronological order. Selected data are summarised in Table 1.

\section{GENERATION I}

The proband was a 74 year old woman (I-2). At the time of this investigation she had symptoms of heart failure and was in functional class II (New York Heart Association). On cardiac auscultation she had an apical systolic murmur grade $2 / 6$ and her electrocardiogram showed atrial fibrillation and ST segment elevation in precordial leads V2-V4. A chest $x$ ray film showed an enlarged heart with a total volume of $1400 \mathrm{ml}$ (normal volume $830 \mathrm{ml} / \mathrm{m}^{2}$ ). An echocardiogram showed a dilated left atrium (diameter $70 \mathrm{~mm}$ ) and thickening of the interventricular septum $(17 \mathrm{~mm})$. The septum:posterior left ventricular wall ratio was $2 \cdot 1$. There was no systolic anterior movement of the mitral valve, but the septum showed decreased thickening fraction. Her husband (I-1) had died of myocardial infarction before the start of this study.

Her sister (I-3) had a 30 year history of cardiac failure, and had been treated with digoxin and diuretics. She had a grade $1 / 6$ systolic heart murmur and her electrocardiogram showed left bundle branch block. The echocardiogram showed a dilated left ventricle with general hypokinesia. There were no valve abnormalities and she had no symptoms of angina pectoris. The findings in I-3 were compatible with congestive cardiomyopathy.

I-4 had no symptoms of cardiac disease at the time of study. He had a grade $1 / 6$ systolic heart murmur and an electrocardiogram showed right bundle branch block. An echocardiogram showed increased thickness of the anterolateral wall of the left ventricle. There was no evidence of left ventricular outflow obstruction. I-4 has three children (not shown on the pedigree). His daughter aged 29 years had no symptoms or signs of cardiac disease. His son aged 27 years had no symptoms of heart disease, but the echocardiogram showed asymmetric septal hypertrophy with a septum:posterior left ventricular wall ratio of $1 \cdot 5$. His youngest son aged 26 years had normal left ventricular dimensions, but the electrocardiogram showed frequent ventricular extrasystoles and episodes of ventricular bigeminy. I-5 had a 15 year history of hypertension. She had no symptoms or signs of cardiomyopathy. I-6 died suddenly at the age of 45 years while performing moderate physical exercise. He had had no symptoms of severe illness. He had five children (not shown on the pedigree) and three were examined. A son aged 31 years had echocardiographic signs of hypertrophic cardiomyopathy, with a septal thickness of $15 \mathrm{~mm}$, while two younger daughters had no evidence of cardiac disease. I-7 died at the age of 36 years from cancer.

\section{GENERATION II}

The proband (I-2) has had 14 children of whom seven had died by the time this investigation was started. One (II-5) was stillborn, and two died when very young; II-6 had a fatal accident, and II-15 died from pneumonia. Two brothers (II-1 and II-2) died suddenly at the ages of 22 and 11 years. They had had no symptoms of severe disease. II-3 was

Table 1 Clinical, electrocardiographic, and echocardiographic findings

\begin{tabular}{|c|c|c|c|c|c|c|c|c|c|}
\hline \multirow{3}{*}{$\begin{array}{l}\text { Generation } \\
\mathrm{I}\end{array}$} & \multirow{2}{*}{\multicolumn{3}{|c|}{$\begin{array}{l}\text { Pedigree No, } \\
\text { sex, and age } \\
(y r)\end{array}$}} & \multirow{3}{*}{$\begin{array}{l}\text { Symptoms } \\
\text { Heart failure } \\
0 \\
----\end{array}$} & \multirow{3}{*}{$\begin{array}{l}\text { Electrocardiogram } \\
\text { AF, ST elevation V2-V4, } \\
\text { RBBB, LAD }\end{array}$} & \multicolumn{3}{|c|}{ Echocardiographic data } & \multirow{3}{*}{$\begin{array}{l}\text { Status } \\
\text { Alive } \\
\text { Alive }\end{array}$} \\
\hline & & & & & & \multirow{2}{*}{$\begin{array}{l}I V S(\mathrm{~mm}) \\
17 \\
16 \\
-\end{array}$} & \multirow{2}{*}{$\begin{array}{l}I V S / P W \\
2 \cdot 1 \\
1 \cdot 8\end{array}$} & \multirow{2}{*}{$\begin{array}{l}S A M \\
0 \\
0\end{array}$} & \\
\hline & $\begin{array}{l}2 \\
4\end{array}$ & $\begin{array}{l}\mathbf{F} \\
\mathbf{M}\end{array}$ & $\begin{array}{l}74 \\
56\end{array}$ & & & & & & \\
\hline \multirow[t]{3}{*}{$\overline{\text { II }}$} & $\begin{array}{r}3 \\
11 \\
19\end{array}$ & $\begin{array}{l}\mathbf{M} \\
\mathbf{M} \\
\mathbf{F}\end{array}$ & $\begin{array}{l}38 \\
46 \\
40\end{array}$ & $\begin{array}{l}\text { AP } \\
\text { AP } \\
0\end{array}$ & $\begin{array}{l}\text { LVH, LVS } \\
\text { AVB I, LVH, LVS } \\
\text { T neg V3, V4; isoelectric } \\
\text { V5, V6 }\end{array}$ & $\begin{array}{l}\text { NA } \\
25 \\
10\end{array}$ & $\begin{array}{l}\text { NA } \\
2 \cdot 8 \\
1 \cdot 4\end{array}$ & $\begin{array}{l}\text { NA } \\
+ \\
0\end{array}$ & $\begin{array}{l}\text { Dead } \\
\text { Alive } \\
\text { Alive }\end{array}$ \\
\hline & 20 & $\mathbf{M}$ & 38 & $\mathbf{A P}$ & $\begin{array}{l}\text { QI, aVL; non-specific } \\
\text { ST changes V3-V5 }\end{array}$ & 33 & $3 \cdot 3$ & + & Alive \\
\hline & 22 & $\mathbf{M}$ & 34 & 0 & $\begin{array}{l}\text { QII, III, aVF; T neg I, } \\
\text { aVL, V3, V4; RBBB }\end{array}$ & 14 & $1 \cdot 8$ & 0 & Alive \\
\hline$\overline{\text { III }}$ & $\begin{array}{l}23 \\
24\end{array}$ & $\begin{array}{l}\mathbf{M} \\
\mathbf{M}\end{array}$ & $\begin{array}{l}16 \\
11\end{array}$ & $\begin{array}{l}0 \\
0\end{array}$ & T neg V3 & $\begin{array}{r}13 \\
4\end{array}$ & $\begin{array}{l}1 \cdot 6 \\
1 \cdot 0\end{array}$ & $\begin{array}{l}0 \\
0\end{array}$ & $\begin{array}{l}\text { Alive } \\
\text { Alive }\end{array}$ \\
\hline
\end{tabular}

AF, atrial fibrillation; AP, angina pectoris; AVB I, atrioventricular block grade I; IVS interventricular septum; LAD, left axis deviation; LVH, left ventricular hypertrophy; LVS, left ventricular strain; PW, posterior left ventricular wall; RBBB, right bundle branch block; SAM, systolic anterior movement of mitral valve; + , present; 0 , absent; NA, not available. 
referred to hospital in 1967 at the age of 31 years. He had disabling symptoms of angina pectoris and clinical examination showed findings typical of hypertrophic cardiomyopathy with an apical systolic ejection murmur grade 4/6. Haemodynamic and angiographic studies confirmed the diagnosis. There was a peak systolic left ventricular outflow gradient of $65 \mathrm{~mm} \mathrm{Hg}$ at rest which was reduced to $20 \mathrm{~mm} \mathrm{Hg}$ after an oral dose of $40 \mathrm{mg}$ propranolol. He was treated with propranolol, but died suddenly seven years later at the age of 38 years.

II-11 was admitted to hospital at the age of 40 years. He had a 15 year history of angina pectoris. Clinical examination showed a systolic ejection murmur grade 3/6. Echocardiography showed asymmetric septal hypertrophy (Fig. 2) and this was verified on cardiac catheterisation. A peak systolic subvalvar aortic gradient at rest of $56 \mathrm{~mm} \mathrm{Hg}$ was reduced to $24 \mathrm{~mm} \mathrm{Hg}$ after $8 \mathrm{mg}$ of intravenous propranolol. Five years later he developed atrial fibrillation which was successfully treated with direct current cardioversion. $\mathrm{He}$ is now being treated with amiodarone and a small dose of propranolol. II-14 died suddenly at the age of 40 years. She was known to have a systolic cardiac murmur, but no signs of severe disease. II-19 had no symptoms of heart disease, but the electrocardiogram showed $T$ wave inversion in precordial leads $V 3$ and V4 and an isoelectric T wave in V5 and V6. The interventricular septum was normal $(10 \mathrm{~mm})$ at end diastole and the septum:posterior left ventricular wall ratio was 1.4 .

II-20 had a four year history of angina pectoris when he was admitted to hospital at the age of 37 years. He had an apical systolic murmur grade $4 / 6$ and echocardiography showed systolic anterior movement of the mitral valve and thickening of the interventricular septum (Fig. 3). Haemodynamic studies showed a peak left ventricular outflow gradient in systole of $43 \mathrm{~mm} \mathrm{Hg}$ which was reduced to $15 \mathrm{~mm} \mathrm{Hg}$ after $4 \mathrm{mg}$ of intravenous propranolol. He has since been treated with oral propranolol. II-22 had no symptoms of heart disease at the time of this investigation. Examination of the heart showed a systolic murmur grade $2 / 6$. The electrocardiogram had abnormal $Q$ waves in the inferior leads, $T$ wave inversion in precordial leads, and evidence of right bundle branch block. The echocardiogram showed thickening of the interventricular septum (14 mm), and the septum:posterior left ventricular wall ratio was $1 \cdot 8$. There was no systolic anterior movement of the mitral valve and the increased septal thickness was most pronounced in the apical region. No family members with evidence of hypertrophic cardiomyopathy had essential hypertension, and the three members in whom cardiac catheterisation was per- formed had normal coronary angiograms. II-8, II10 , and II-16 had no symptoms or signs of hypertrophic cardiomyopathy. None of the nine spouses in generation II had symptoms or signs of cardiac disease.

GENERATION III

Generation III consisted of 31 members. Their ages ranged from 1 to 31 years. None had clinical symptoms of cardiac disease. An echocardiogram of III23 , a boy aged 16, showed thickening of the interventricular septum $(13 \mathrm{~mm})$ and a septum:posterior left ventricular wall ratio of $1 \cdot 6$. There was no systolic anterior movement of the mitral valve and the electrocardiogram was normal. His brothers and sister had no clinical or echocardiographic signs of cardiac disease. Both III-4 and III-14 had a septum:posterior left ventricular wall ratio of 1.4 but no increased septal thickness. According to our definition III-14, a 17 year old girl, probably had hypertrophic cardiomyopathy. The spouses in this generation were not examined.

\section{GENERATION IV}

Generation IV consisted of 10 apparently healthy young children. None of them had signs or symptoms of hypertrophic cardiomyopathy.

\section{SEARCH FOR GENETIC LINKAGE}

HLA typing was restricted to members of generations I and II and to selected members of generation III. The HLA haplotypes of I-1 and II-3 could be deduced from typing their spouses and children. Table 2 summarises the results of the HLA typing. All definitely affected members in generations I and II carry the HLA haplotype A1 B37 DR7. Two apparently unaffected members (I-5 and II-16), however, also have this haplotype. The only family member of generation III (III-23) who both met the criteria for being classified as having hypertrophic cardiomyopathy and had HLA typing, has inherited the alternative HLA haplotype (A11 B7 DR2) from his maternal grandmother (I-2), who also had hypertrophic cardiomyopathy.

\section{Discussion}

The frequency of hypertrophic cardiomyopathy was high in generations I and II. The severity and distribution of left ventricular hypertrophy varied, but members of generation II were most severely affected. In this generation, two living brothers (II11 and II-20) and one brother who died suddenly (II-3) had definite signs of hypertrophic cardiomyopathy with pronounced left ventricular outflow obstruction. They presented clinically with symp- 


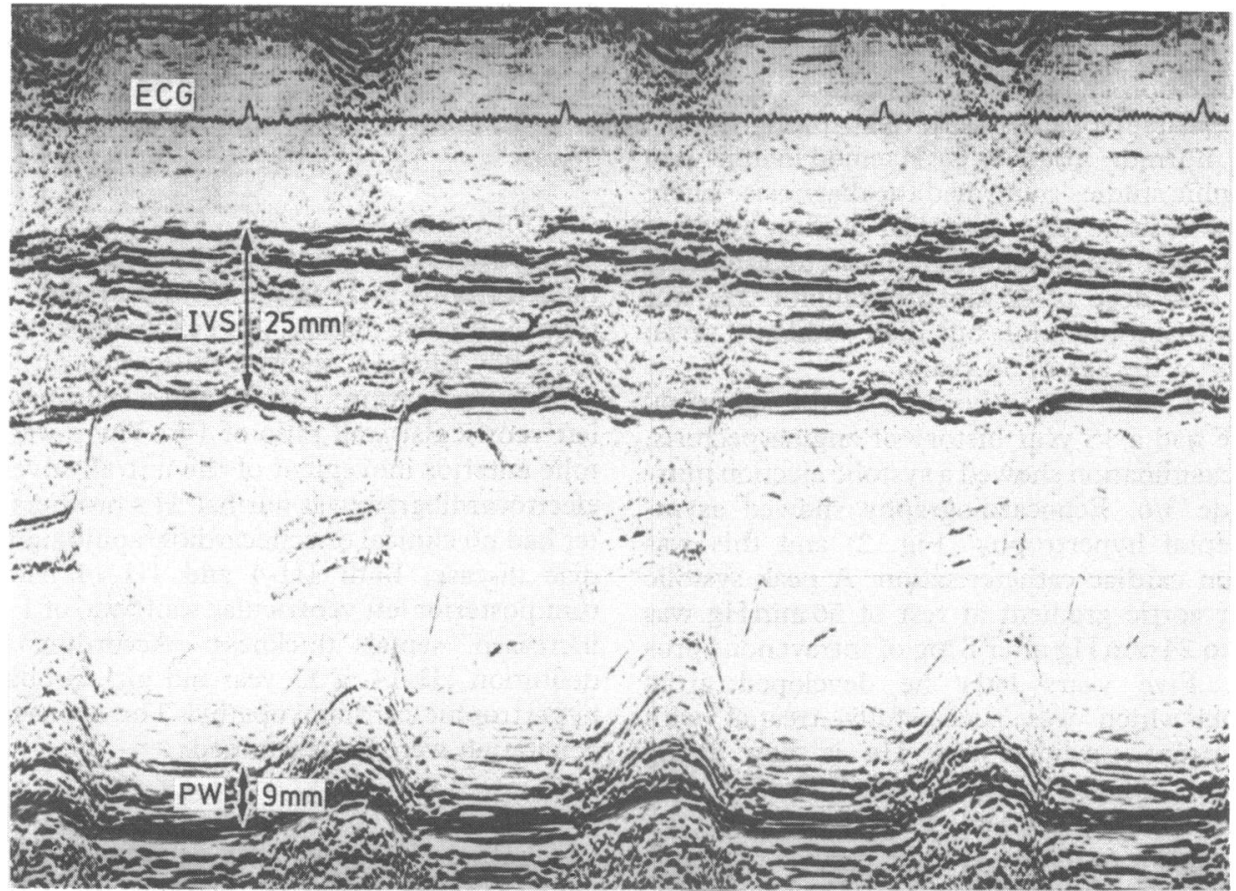

Fig. $2 M$ mode echocardiogram of case II-11 with definite evidence of asymmetric septal hypertrophy. IVS, interventricular septum; $P W$, posterior left ventricular wall; $E C G$, electrocardiogram.

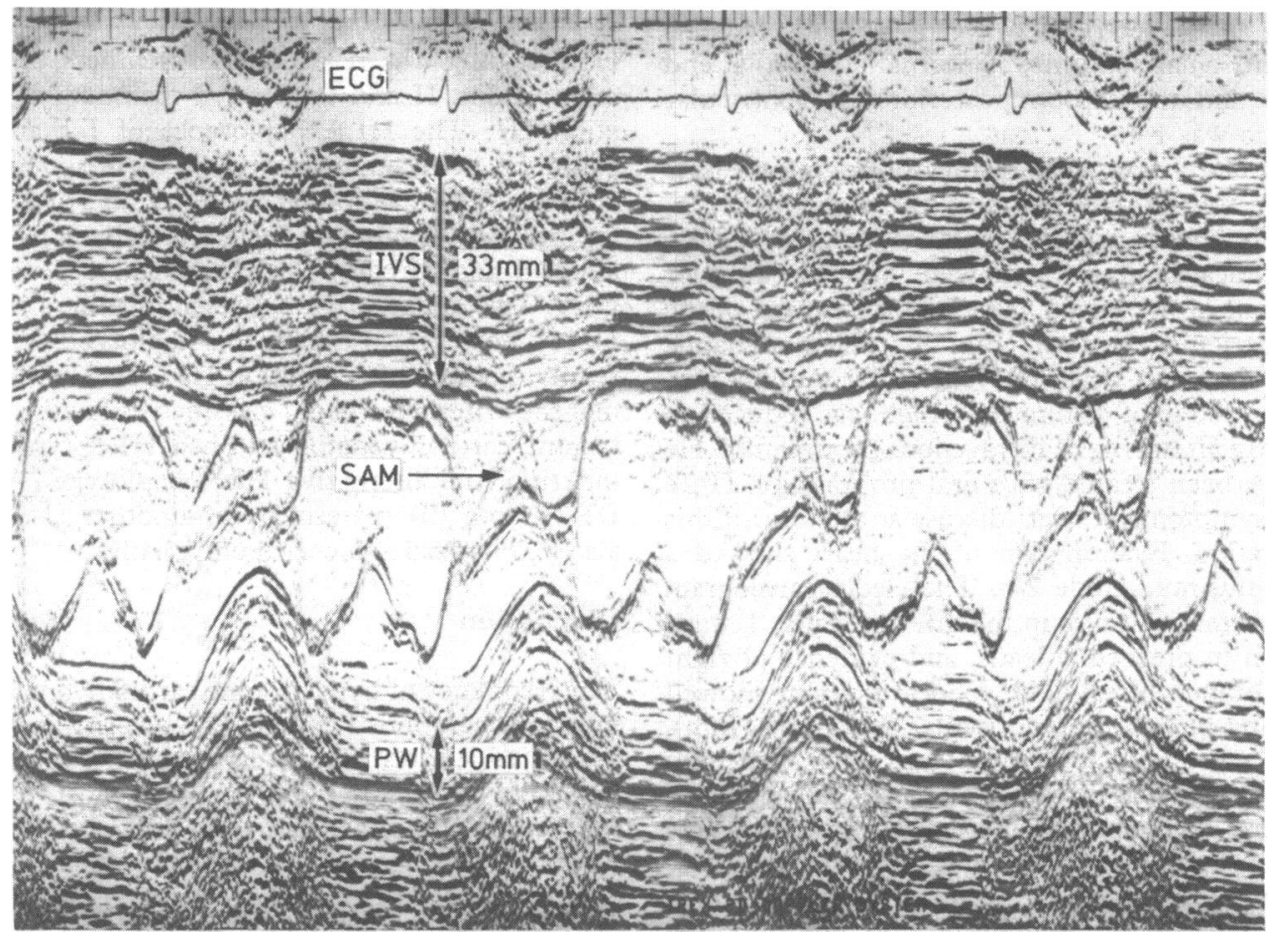

Fig. 3 mode echocardiogram of case II-20 showing an enormous increase in septal thickness (33 mm) and evidence of systolic anterior movement of the mitral valve (SAM) which indicates left ventricular outflow obstruction. IVS, interventricular septum; PW, posterior left ventricular wall; ECG, electrocardiogram. 
Table 2 HLA histocompatibility markers in selected family members

\begin{tabular}{|c|c|c|c|c|c|c|c|c|}
\hline \multirow{2}{*}{$\begin{array}{l}\text { Generation } \\
\text { I }\end{array}$} & \multicolumn{3}{|c|}{$\begin{array}{l}\text { Pedigree No, } \\
\text { sex, and age (yr) }\end{array}$} & \multicolumn{3}{|c|}{ HLA haplotypes } & \multirow{2}{*}{$\begin{array}{l}\text { HCM } \\
\text { NA }\end{array}$} & \multirow{2}{*}{$\begin{array}{l}\text { Genes coupled } \dagger \\
\text { Spouse }\end{array}$} \\
\hline & 1 & $\mathbf{M}$ & 67 & \multirow{5}{*}{$\begin{array}{l}\text { A2 } \\
\text { A19 } \\
\text { A11 } \\
\text { A1 } \\
\text { A11 } \\
\text { A2 } \\
\text { A11 } \\
\text { A1 } \\
\text { A11 } \\
\text { A1 }\end{array}$} & \multirow{5}{*}{$\begin{array}{l}\text { B7 } \\
\text { B18 } \\
\text { B7 } \\
\text { B37 } \\
\text { B7 } \\
\text { B37 } \\
\text { B7 } \\
\text { B37 } \\
\text { B7 } \\
\text { B37 }\end{array}$} & \multirow{5}{*}{$\begin{array}{l}\text { DR4 } \\
\text { DR3 } \\
\text { DR2 } \\
\text { DR7 } \\
\text { DR2 } \\
\text { DR7 } \\
\text { DR2 } \\
\text { DR7 } \\
\text { DR2 } \\
\text { DR7 }\end{array}$} & & \\
\hline & 2 & F & 74 & & & & + & Index \\
\hline & 3 & F & 60 & & & & 0 & Yes?‡ \\
\hline & 4 & $\mathbf{M}$ & 56 & & & & + & Yes \\
\hline & 5 & F & 52 & & & & 0 & No \\
\hline \multirow[t]{9}{*}{ II } & 3 & $\mathbf{M}$ & 38 & \multirow{9}{*}{$\begin{array}{l}\text { A2 } \\
\text { A1 } \\
\text { A19 } \\
\text { A11 } \\
\text { A19 } \\
\text { A11 } \\
\text { A19 } \\
\text { A1 } \\
\text { A19 } \\
\text { A1 } \\
\text { A2 } \\
\text { A1 } \\
\text { A2 } \\
\text { A11 } \\
\text { A2 } \\
\text { A1 } \\
\text { A2 } \\
\text { A1 }\end{array}$} & \multirow{9}{*}{$\begin{array}{l}\text { B7 } \\
\text { B37 } \\
\text { B18 } \\
\text { B7 } \\
\text { B18 } \\
\text { B7 } \\
\text { B18 } \\
\text { B37 } \\
\text { B18 } \\
\text { B37 } \\
\text { B15 } \\
\text { B7 } \\
\text { B7 } \\
\text { B7 } \\
\text { B7 } \\
\text { B37 } \\
\text { B7 } \\
\text { B37 }\end{array}$} & \multirow{9}{*}{$\begin{array}{l}\text { DR4 } \\
\text { DR7 } \\
\text { DR3 } \\
\text { DR2 } \\
\text { DR3 } \\
\text { DR2 } \\
\text { DR3 } \\
\text { DR7 } \\
\text { DR3 } \\
\text { DR7 } \\
\text { DR4 } \\
\text { DR4 } \\
\text { DR4 } \\
\text { DR2 } \\
\text { DR4 } \\
\text { DR7 } \\
\text { DR4 } \\
\text { DR7 } \\
\text { - - }\end{array}$} & + & Yes \\
\hline & 8 & F & 55 & & & & 0 & Yes \\
\hline & 10 & $\mathbf{F}$ & 52 & & & & 0 & Yes \\
\hline & 11 & $\mathbf{M}$ & 46 & & & & + & Yes \\
\hline & 16 & $\mathbf{M}$ & 42 & & & & 0 & No \\
\hline & 18 & $\mathbf{M}$ & 44 & & & & 0 & Spouse \\
\hline & 19 & $\mathbf{F}$ & 40 & & & & 0 & No§ \\
\hline & 20 & $\mathbf{M}$ & 38 & & & & + & Yes \\
\hline & 22 & $\mathbf{M}$ & 34 & & & & + & ----- \\
\hline \multirow[t]{3}{*}{$\overrightarrow{\mathrm{III}}$} & 22 & $\mathbf{F}$ & 18 & \multirow{3}{*}{$\begin{array}{l}\text { A11 } \\
\text { A2 } \\
\text { A11 } \\
\text { A2 } \\
\text { A1 } \\
\text { A2 }\end{array}$} & \multirow{3}{*}{$\begin{array}{l}\text { B7 } \\
\text { B15 } \\
\text { B7 } \\
\text { B15 } \\
\text { B7 } \\
\text { B7 }\end{array}$} & \multirow{3}{*}{$\begin{array}{l}\text { DR2 } \\
\text { DR4 } \\
\text { DR2 } \\
\text { DR4 } \\
\text { DR4 } \\
\text { DR4 }\end{array}$} & 0 & No?§ \\
\hline & 23 & $\mathbf{M}$ & 16 & & & & + & Yes§ \\
\hline & 24 & $\mathbf{M}$ & 11 & & & & 0 & NA§ \\
\hline
\end{tabular}

HCM, hypertrophic cardiomyopathy; +, present; 0 , absent; NA, data not available; thaplotypes deduced from family typing.

†Assumption: The gene locus for hypertrophic cardiomyopathy is located near the HLA complex on chromosome number 6 . I-2 is used as an index person. "Yes" indicates either haplotype A1 B37 DR7 and hypertrophic cardiomyopathy, or A11 B7 DR2 and no disease. Observation of co-inheritance is compatible with, but does not prove, genes linkage (no recombination). "No" indicates either haplotype A11 B7 DR2 and hypertrophic cardiomyopathy, or A1 B37 DR7 and no disease. Observation indicates a crossover during sex cell formation in parent (recombination).

¥Insufficient information. Haplotype A2 B37 DR7 may represent a third distinct haplotype in this sibship or be the product of a crossover within the HLA complex.

$\$ I I-19$ is healthy, but she has a son (III-23) with cardiomyopathy. II-19 must therefore have received the gene for hypertrophic cardiomyopathy with the A11 B7 DR2 haplotype from her affected mother I-2 (recombination), and transmitted both traits together to her son (non-recombination). Her daughter III-22 is too young to yield information, and III-24 has not inherited any of the HLA haplotypes from his maternal grandmother.

toms of coronary heart disease. The youngest brother (II-22) had no symptoms of heart disease at the time of this study but the electrocardiogram was abnormal (Table 1) and the echocardiogram showed asymmetric septal hypertrophy without outflow obstruction.

There was also a high frequency of sudden unexpected deaths in the family. Two brothers (II-1 and II-2) died suddenly at the age of 22 and 11 years, respectively, one of them while playing in the schoolyard. Their sister (II-4) died suddenly at the age of $\mathbf{4 0}$ years. She had a systolic cardiac murmur but no symptoms of heart disease. In generation I, I-6 died suddenly at the age of 45 years, and an echocardiographic study of his son showed signs of hypertrophic cardiomyopathy. Sudden death is common in families with hypertrophic cardio- myopathy, probably as a result of ventricular arrhythmias or acute haemodynamic changes. It is likely that the three siblings in generation II and their uncle (I-6) died of a cardiac arrhythmia, and we assume that they all had hypertrophic cardiomyopathy. The distribution of affected family members in generations I and II is compatible with autosomal dominant inheritance. We examined the three children of I-4 and three of the five children of I-6. All were symptom free. In both sibships (not shown on the pedigree) a son with definite asymmetric septal hypertrophy was found. This father to son transmission of the trait excluded $\mathbf{X}$ linked inheritance but was consistent with the postulated autosomal dominant mode of inheritance.

Kishimoto et al suggested that a gene locus for hypertrophic cardiomyopathy may be located on 
chromosome number 6 within mapable distance of the HLA complex in some families. ${ }^{6}$ Table 2 outlines the distribution of HLA haplotypes in some family members. Table 2 also indicates whether the two traits were inherited together as would have been expected if there were close genetic linkage. If the gene for hypertrophic cardiomyopathy is located on chromosome number 6 , very close to the HLA complex, a particular HLA haplotype should consistently be found together with the gene for hypertrophic cardiomyopathy in a given family. The further apart on a chromosome two traits are located, the more frequently they will tend to separate during the formation of sex cells. Genes far apart on the same chromosome or situated on different chromosomes segregate independently and with equal frequency to the offspring.

In this family, eleven people may be informative (Table 2). Because the observed distribution (three recombinants, eight non-recombinants) or a more skewed distribution would occur by chance in $11.3 \%$ of such sets of observations this distribution may have arisen by chance. Thus, HLA typing in this family was not useful for the identification of presymptomatic gene carriers of hypertrophic cardiomyopathy. Loose genetic linkage between the two traits, however, cannot yet be excluded. In this family more information may be gained by extending the HLA typing to other family members (for example to III-14, descendants of I-3, I-4, I-5, and I-6) and by including in the analysis other genetic chromosome number 6 markers outside the HLA complex. The distribution of HLA haplotypes among the siblings of I-2 could then be clarified, and the assumed crossover events in the vicinity of the HLA complex on chromosome number 6 (sex cells from I-2 to II-16 and II-19) may be corroborated. Formal linkage analysis will be performed in this family when such information is available.

A high frequency of hypertrophic cardiomyopathy would be expected in generations III and IV, but only a 16 year old boy (III-23) and the 17 year old girl (III-14) showed evidence of asymmetric septal hypertrophy. This observation suggests that other factors in addition to a genetic predisposition may be necessary for clinical hypertrophic cardiomyopathy to develop. This accords with studies by Emanuel $e t a l$ who have shown that clinical hypertrophic cardiomyopathy may not become evident until adolescence or even early adult life. ${ }^{12}$ Thus, the development of septal hypertrophy may be age dependent. There is strong evidence that catecholamines can stimulate the growth of septal tissue and thereby accelerate the disease process. Data obtained by infusion of noradrenaline in dogs raise the possibility that the interventricular septum is more sensitive to beta adrenergic stimulation than either the right ventricle or the free wall of the left ventricle. ${ }^{13}$ This suggests that increased sympathetic activity or increased sensitivity to catecholamines are possible mechanisms for the development of hypertrophic cardiomyopathy in the human heart. Studies by Yamori et al suggested that the beta adrenergic effects of noradrenaline were more potent than its alpha effects in inducing cardiac hypertrophy. ${ }^{14}$ This may explain the beneficial haemodynamic effect of beta blockers in patients with hypertrophic cardiomyopathy. In the present family three brothers (II-3, II-11, II-20) in generation II had evidence of left ventricular outflow obstruction. They were all examined by cardiac catheterisation and there was a substantial reduction in the peak systolic gradient after administration of propranolol.

Echocardiography offers a unique method of diagnosing patients with established hypertrophic cardiomyopathy. The severity of myocardial disease may be assessed and future management guided. This method, however, has not been useful in identifying young patients at risk for developing this disease. In the present family, only three family members (II-22, III-14, and III-23) and the sons of I-4 and I- 6 were diagnosed by echocardiography as having hypertrophic cardiomyopathy without clinical symptoms of cardiac disease. Because there is evidence for an autosomal dominant mode of inheritance of the disease in this family, we expect that many members of the two younger generations will develop signs of the disease as adults. Longitudinal echocardiographic studies combined with functional assessments may be of some value in increasing the diagnostic rate in these younger age groups. No other existing methods are likely to be more useful in the diagnostic evaluation of hypertrophic cardiomyopathy.

\section{References}

1 Frank S, Braunwald E. Idiopathic hypertrophic subaortic stenosis: clinical analysis of 126 patients with emphasis on the natural history. Circulation 1968; 37: 759-88.

2 Clark CE, Henry WL, Epstein SE. Familial prevalence and genetic transmission of idiopathic hypertrophic subaortic stenosis. $N$ Engl f Med 1973; 289: 709-14.

3 Van Dorp WG, ten Cate FJ, Vletter WB, Dohmen H, Roelandt J. Familial prevalence of asymmetric septal hypertrophy. Eur f Cardiol 1976; 43: 349-57.

4 Emanuel R, Withers R, O'Brien K. Dominant and recessive modes of inheritance in idiopathic cardiomyopathy. Lancet 1971; ii: 1065-7.

5 Matsumori A, Kawai C, Wakabayashi A, et al. HLA- 
DRW4 antigen linkage in patients with hypertrophic obstructive cardiomyopathy. Am Heart $\mathcal{f}$ 1981; 101: 14-6.

6 Kishimoto C, Kaburagi T, Takayama S, et al. Two forms of hypertrophic cardiomyopathy distinguished by inheritance of HLA haplotypes and left ventricular outflow tract obstruction. Am Heart $\mathcal{f}$ 1983; 105: 988-94.

7 Gardin JM, Gottdiener JS, Radvany R, Maron BJ, Lesch M. HLA linkage vs association in hypertrophic cardiomyopathy. Chest 1982; 81: 466-72.

8 Maron BJ, Nichols PF III, Pickle LW, Wesley YE, Mulvihill JJ. Patterns of inheritance in hypertrophic cardiomyopathy: assessment by $\mathrm{M}$-mode and Twodimensional echocardiography. Am $\mathcal{f}$ Cardiol 1984; 53: 1087-94.

9 Sahn D, DeMaria A, Kisslo J, Weyman A. Recommendations regarding quantitation in $\mathrm{M}$-mode echocardiography. Results of a survey of echocardiographic measurements. Circulation 1978; 58: 1072-83.
10 Henry WL, Gardin JM, Ware JH. Echocardiographic measurements in normal subjects from infancy to old age. Circulation 1980; 62: 1054-61.

11 Albrechtsen D, Bratlie A, Nousiainen H, Solheim BG, Winter N, Thorsby E. Serological typing of HLA-D: predictive value in mixed lymphocyte cultures (MLC). Immunogenetics 1978; 6: 91-100.

12 Emanuel R, Marcomichelakis J, Withers R, O'Brien K. Asymmetric septal hypertrophy and hypertrophic cardiomyopathy. Br Heart $f$ 1983; 49: 309-16.

13 Raum WJ, Laks MM, Garner D, Swerdloff RS. Beta adrenergic receptor and cyclic AMP alterations in the canine ventricular septum during long-term norepinephrine infusion: implication for hypertrophic cardiomyopathy. Circulation 1983; 68: 693-9.

14 Yamori Y, Tarazi RC, Ooshima A. Effect of betareceptor blocking agents on cardiovascular structural changes in spontaneous and noradrenaline-induced hypertension in rats. Clin Sci 1980; 59 (suppl 6): 457-605. 